\title{
Microbiological assessment and evaluation of rehydration instructions on powdered infant formulas, follow-up formulas, and infant foods in Malaysia
}

\author{
N. Abdullah Sani, ${ }^{* 1}$ S. H. P. Hartantyo, ${ }^{*}$ and S. J. Forsythe $†$ \\ *Food Science Programme, School of Chemical Sciences and Food Technology, Faculty of Science and Technology, \\ Universiti Kebangsaan Malaysia, 43600 Bangi, Selangor, Malaysia \\ †School of Science and Technology, Nottingham Trent University, Clifton Lane, Nottingham, NG11 8NS, United Kingdom
}

\section{ABSTRACT}

A total of 90 samples comprising powdered infant formulas $(\mathrm{n}=51)$, follow-up formulas $(\mathrm{n}=21)$, and infant foods $(\mathrm{n}=18)$ from 15 domestic and imported brands were purchased from various retailers in Klang Valley, Malaysia and evaluated in terms of microbiological quality and the similarity of rehydration instructions on the product label to guidelines set by the World Health Organization. Microbiological analysis included the determination of aerobic plate count (APC) and the presence of Enterobacteriaceae and Cronobacter spp. Isolates of interest were identified using ID $32 \mathrm{E}$ (bioMérieux France, Craponne, France). In this study, $87 \%$ of powdered infant formulas, follow-up formulas, and infant foods analyzed had an APC below the permitted level of $<10^{4} \mathrm{cfu} / \mathrm{g}$. These acceptable APC ranged between $<10^{2}$ to $7.2 \times 10^{3} \mathrm{cfu} / \mathrm{g}$. The most frequently isolated Enterobacteriaceae was Enterobacter cloacae, which was present in 3 infant formulas and 1 infant food tested. Other Enterobacteriaceae detected from powdered infant and follow-up formulas were Citrobacter spp., Klebsiella spp., and other Enterobacter spp. No Cronobacter species were found in any samples. Rehydration instructions from the product labels were collated and it was observed that none directed the use of water with a temperature $>70^{\circ} \mathrm{C}$ for formula preparation, as specified by the 2008 revised World Health Organization guidelines. Six brands instructed the use of water at 40 to $55^{\circ} \mathrm{C}$, a temperature range that would support the survival and even growth of Enterobacteriaceae.

Key words: powdered infant formula, follow-up formula, infant foods, rehydration instructions

Received February 3, 2012.

Accepted September 23, 2012.

${ }^{1}$ Corresponding author: norra@ukm.my

\section{INTRODUCTION}

In terms of food safety, infants and children are considered to be a part of the high-risk group of individuals, as their immune systems may not yet be fully developed. Infants and young children are especially vulnerable to diarrheal illnesses when introduced to fluids and foods as they are weaned from breastfeeding to a mixed diet (Marino, 2007). In food, pathogens can grow at room temperature. Further, elevated temperatures that are typical in tropical countries can hasten pathogen multiplication (Tirado et al., 2010).

One of the pathogens of concern is the opportunistic Cronobacter (formerly Enterobacter sakazakii), which has gained attention in the past decade by its association with infant infections through contaminated infant formula (Joseph and Forsythe, 2011; Kucerova et al., 2011). These organisms have been observed to persist in dry environments such as powdered foods and grow rapidly in reconstitution (Iversen and Fanning, 2009). An early survey on the presence of Enterobacteriaceae in powdered infant formula (PIF) by Muytjens et al. (1988) reported that $52.2 \%$ of the samples contained the organisms. The following year, a case of infant formula milk believed to be contaminated with Enterobacteriaceae (Cronobacter) during the manufacturing process (Simmons et al., 1989) and 3 cases of neonatal meningitis caused by Cronobacter found in dried infant formula in Iceland (Biering et al., 1989) were reported. Isolation of Cronobacter in $16.6 \%$ of PIF samples was reported in 2004 (Iversen and Forsythe, 2004).

In 2008, the Food and Agriculture Organization of the United Nations/World Health Organization (FAO/ WHO) issued a call for data on Cronobacter occurrence in PIF (intended target age $<6 \mathrm{mo}$ ) and follow-up formula (FOF; intended target age $>6 \mathrm{mo}$ ). In response, an international survey involving 8 laboratories in 7 different countries (including Malaysia) was coordinated to determine the presence of Cronobacter sakazakii and other Cronobacter spp. in FOF and other infant foods. Initial investigations in this study were done in line with the $\mathrm{FAO} / \mathrm{WHO}$ request and were subsequently 
published (Chap et al., 2009). However, given the lack of published information in Malaysia with regard to the presence of Cronobacter, the survey was extended to a wider range of PIF, FOF, and infant or weaning foods (IF) available in the country.

Aside from the intrinsic presence of pathogens, improper handling of infant-related food, such as inadequate cleaning of bottles, multiple reheating, or inappropriate rehydration procedures may also favor the proliferation of harmful bacteria. For this reason, the WHO in 2007 released both printed and online materials to guide the general public about safe milk handling (WHO, 2007a,b). It is uncertain how widely these guidelines have been distributed and adopted for product instructions for the preparation of infant foods. It is worthwhile, therefore, to check whether the instructions provided on different products are in line with these WHO recommendations.

It is worth noting that the basic principles of food poisoning and food hygiene in developed and developing countries are the same. However, food safety in developing countries such as Malaysia is more challenging due to the tropical climate. Further, although the basic factors preceding foodborne illness in the tropics are the same as in other places, conditions such as high ambient temperature and humidity, general lack of refrigeration, local habits, impure water, poor sanitary facilities, and profusion of intestinal pathogens and parasites can enhance the dangers (Adams, 2007). This study aims to determine the microbiological quality of PIF and related products commercially available in Malaysia in terms of their aerobic plate count (APC) and the presence of Enterobacteriaceae, especially Cronobacter. This study will provide microbiological surveillance data that may be used to evaluate the suitability of internationally prescribed infant formula handling and management standards to conditions in tropical developing countries.

\section{MATERIALS AND METHODS}

\section{Milk Samples}

A total of 90 samples were analyzed. They comprised PIF $(\mathrm{n}=51)$, FOF $(\mathrm{n}=21)$, and IF $(\mathrm{n}=18)$ from 15 domestic and imported brands purchased from various retailers in Klang Valley, Malaysia. By definition, PIF is a formula intended for use by infants from 0 to $6 \mathrm{mo}$, FOF is formula for use by infants from 6 mo onward, and infant food can be any food other than breast milk or infant formula that is made specifically for infants. Whenever available, 5 samples from identical production batches were obtained. Only 1 sample was analyzed from some PIF brands, as they were provided by local distributors. Product ingredients, reconstitution instructions, and products containing special components such as probiotic cultures were recorded.

\section{Microbiological Analysis}

Microbiological analysis conducted in this study included the determination of APC and the presence of Enterobacteriaceae and Cronobacter spp. Following the surface spread plate method (Roberts and Greenwood, 2003), the APC in milk and infant food samples were determined. Twenty-five grams of each sample was added to 225-mL portions of Maximum Recovery Diluent (MRD; Oxoid Thermo Fisher, Basingstoke, UK) and allowed to rehydrate at room temperature for 10 min. After rehydration, the rehydrated milk was serial diluted in MRD until a $10^{-5}$ dilution was obtained. From each MRD dilution, 0.1-mL portions were spread onto plate count agar (Oxoid Thermo Fisher). The plate count agar was then allowed to dry, incubated overnight at $37^{\circ} \mathrm{C}$, and discrete colonies thereafter counted. All samples were analyzed in duplicate.

To determine the presence of Cronobacter and other Enterobacteriaceae in the milk and infant food, samples were analyzed as previously described by Chap et al. (2009). Samples were preenriched by suspending $25 \mathrm{~g}$ in $225 \mathrm{~mL}$ of buffered peptone water (Oxoid Thermo Fisher) and incubated at $37^{\circ} \mathrm{C}$ for 18 to $24 \mathrm{~h}$. After incubation, $10-\mathrm{mL}$ portions were transferred into 90$\mathrm{mL}$ Enterobacteriaceae enrichment (EE; Oxoid Thermo Fisher) broth and incubated overnight at $37^{\circ} \mathrm{C}$ as an enrichment step.

To detect Enterobacteriaceae, 1-mL portions of EE broth were pipetted onto separate Petri dishes and mixed with 10 to $15 \mathrm{~mL}$ of molten, cooled violet red bile glucose agar (VRBGA; Oxoid Thermo Fisher) and allowed to set. The solidified medium was then overlaid with an additional $10 \mathrm{~mL}$ of molten, cooled VRBGA and allowed to set. For Cronobacter detection, a loopful of EE broth was streaked on Brilliance Enterobacter sakazakii chromogenic DFI agar (Oxoid Thermo Fisher). The inoculated plates were incubated at $37^{\circ} \mathrm{C}$ overnight. All samples were analyzed in duplicate. Isolates of interest were identified using phenotyping (ID 32E; bioMérieux France, Craponne, France).

\section{RESULTS AND DISCUSSION}

\section{Determination of APC}

The general microbial flora present in 90 samples of PIF, FOF, and IF from 15 different commercial brands were determined (Table 1). From the samples analyzed, 61 had APC less than $10^{2} \mathrm{cfu} / \mathrm{g}, 1$ of the samples 
Table 1. Aerobic plate counts of different infant milk and feed samples

\begin{tabular}{lccccc}
\hline & & \multicolumn{4}{c}{ Aerobic plate count (cfu/g of sample) } \\
\cline { 3 - 6 } Product type & Samples & $<10^{2}$ & $10^{2}$ to $<10^{3}$ & $10^{3}$ to $<10^{4}$ & $>10^{4}$ \\
\hline Infant formula & 51 & 41 & 0 & 10 & 0 \\
Follow-up formula & 21 & 9 & 0 & 5 & 7 \\
Infant food & 18 & 11 & 1 & 1 & 5 \\
Total & 90 & 61 & 1 & 16 & 12 \\
\hline
\end{tabular}

had an APC between $10^{2}$ to $<10^{3} \mathrm{cfu} / \mathrm{g}, 16$ samples had APC between $10^{3}$ to $<10^{4} \mathrm{cfu} / \mathrm{g}$, and 12 samples exceeded the maximum acceptable APC level of $10^{4}$ $\mathrm{cfu} / \mathrm{g}$. It was observed that $87 \%$ (78/90) of the samples had acceptable APC limits of $<10^{4} \mathrm{cfu} / \mathrm{g}$, a guideline of safety against possible food poisoning (HMSO, 1995; Gilbert et al., 2000).

Very high aerobic counts $\left(>10^{4}\right)$ were observed for 7 FOF and 5 IF, in agreement with studies by Chap et al. (2009). The highest APC $\left(4.2 \times 10^{6} \mathrm{cfu} / \mathrm{g}\right)$ was recorded for an infant cereal intended for babies aged 8 to 24 mo. This product was labeled to contain the probiotic Bifidobacterium lactis, but because of the anaerobic nature of this organism, it could not have contributed to the high APC levels. According to the Malaysian regulations (Regulation 26A, Act 281, 1983), food containing bifidobacteria should contain at least $10^{6}$ viable cells per gram (Food Act, 2006) and it has been established that long-term consumption of infant formula milk supplemented with $B$. lactis is safe and well-tolerated by infants (Saavedra et al. 2004). Milk supplemented with probiotics results in certain immunomodulatory effects such as decreased allergic tendencies (Viljanen et al., 2005; Rautava, 2007). The level of Enterobacteriaceae spp. for this product was not quantified, but Enterobacteriaceae, specifically Enterobacter vulneris, was detected using the biochemical test ID 32E.

Further, an infant cereal that contained B. lactis cultures also yielded a relatively high APC of $5.5 \times$ $10^{4} \mathrm{cfu} / \mathrm{g}$. An FOF containing Bifidobacterium longum and Lactobacillus rhamnosus probiotics showed a high APC level of $5.3 \times 10^{5}$. On the other hand, a probioticcontaining FOF yielded an APC $<10^{2} \mathrm{cfu} / \mathrm{g}$, despite having Bifidus cultures in its composition. In this case, the exact Bifidus species was not mentioned.

For PIF, APC ranged between $<10^{2}$ to $7.3 \times 10^{3}$ $\mathrm{cfu} / \mathrm{g}$. Approximately $78 \%$ of these samples had APC $<10^{2} \mathrm{cfu} / \mathrm{g}$, which is reported as undetected according to Codex Alimentarius regulations. For FOF, $43 \%$ of the samples had an APC $<10^{2}$, whereas $14 \%(3 / 21)$ of the samples had APC $>10^{4}$ and, therefore, not meeting standard regulations. Of the $18 \mathrm{IF}$ tested, the APC range was between $<10^{2}$ to $4.6 \times 10^{6} \mathrm{cfu} / \mathrm{g}$, the highest APC for all samples tested. Around $72 \%$ of the IF samples were compliant to Codex Alimentarius regulations for APC.

\section{Detection of Enterobacteriaceae spp.}

The Enterobacteriaceae level is one of the microbiological criteria (ISO, 2004; EC, 2005) prescribed for dried infant formula and dried dietary foods for special medical purposes intended for infants below 6 mo of age; in $10 \mathrm{~g}$ of these dried infant formulas and dietary foods, Enterobacteriaceae should not be present. These regulations further state that if Enterobacteriaceae are present, the presence of Cronobacter should be tested. In this study, Enterobacteriaceae was detected in 13/90 samples, but none were confirmed to contain Cronobacter, following the prescribed method of detection using Cronobacter chromogenic medium (Iversen and Forsythe, 2004).

Further biochemical profiling was conducted using the bioMérieux ID 32E system, in place of the prescribed API 20E system (bioMérieux France), as preliminary studies using well-characterized Cronobacter strains cultures found ID $32 \mathrm{E}$ to more accurately identify the organism. The most frequent organism detected was Enterobacter spp. (5/90 samples), followed by Citrobacter spp. (5/90) and Klebsiella spp. (3/90 samples; Table 2). These results are similar to those obtained by Iversen and Forsythe (2004) who isolated Enterobacteriaceae, including Enterobacter spp., Pantoea spp.,

Table 2. Types of Enterobacteriaceae detected in various milk samples

\begin{tabular}{ll}
\hline $\begin{array}{l}\text { Product type/ } \\
\text { sample code }\end{array}$ & $\begin{array}{l}\text { Enterobacteriaceae } \\
\text { detected }\end{array}$ \\
\hline Infant formula $\mathrm{E}$ & $\begin{array}{l}\text { Citrobacter freundii } \\
\text { Citrobacter amalonaticus } \\
\text { Enterobacter cloacae }\end{array}$ \\
Infant formula $\mathrm{F}$ & $\begin{array}{l}\text { Klebsiella terrigena } \\
\text { Citrobacter freundii }\end{array}$ \\
& Enterobacter cloacae \\
Infant formula G & Klebsiella pneumoniae \\
Infant formula H & $\begin{array}{l}\text { Citrobacter freundii } \\
\text { Follow-up formula J }\end{array}$ \\
Enterobacter cloacae \\
Infant food 2 & Enterobacter vulneris \\
Infant food 11 &
\end{tabular}

${ }^{1}$ Organism detected in 2 samples of the same product type. 
Table 3. Similarity of powdered infant formula (PIF) and follow-up formula (FOF) rehydration instructions to World Health Organization (WHO) guidelines for preparation of

Sample compliance with WHO guidelines ${ }^{2}$

Recommended steps ${ }^{1}$

\begin{tabular}{llllllllllllllll}
\hline 4 & $5^{3}$ & 6 & 7 & 8 & 9 & 10 & $14^{3}$ & 20 & 21 & 22 & 30 & A & B & C & D
\end{tabular}

E F

A. Cleaning and sterilizing feeding and preparation equipment

1. Hands should always be washed thoroughly with soap and water before cleaning and

sterilizing feeding and preparation equipment

2. Wash feeding and preparation equipment

(e.g., cups, bottles, teats, and spoons)

thoroughly in hot soapy water

3. After washing the feeding and preparation equipment, rinse thoroughly in safe water

4. Sterilizing: if using a commercial home

sterilizer (e.g., electric or microwave steam

sterilizer, or chemical sterilizer), follow

manufacturer's instructions. Feeding and

preparation equipment can also be sterilized by boiling

5. Hands should be washed thoroughly with soap and water before removing feeding and preparation equipment from a sterilizer or pan. The use of sterilized kitchen tongs for handling sterilized feeding and preparation handling sterilized feeding a

equipment is recommended
6. Remove feeding and preparation equipment just before it is to be used. If equipment is removed from the sterilizer and not used

immediately, it should be covered and stored

in a clean place. Feeding bottles can be fully assembled

B. Preparing a feed using powdered infant B. Preparing
formula

1. Clean and disinfect a surface on which to prepare the feed

2. Wash hands with soap, water; dry using a clean cloth or single-use napkin

3. Boil a sufficient volume of safe water. If

using an automatic kettle, wait until kettle

switches off; make sure that the water comes to a rolling boil

4. Taking care to avoid scalds, pour the

appropriate amount of boiled water that has been allowed to cool to no less than $70^{\circ} \mathrm{C}$ into a cleaned and sterilized feeding cup or bottle

5. To the water, add the exact amount of formula as instructed on the label

6 . Immediately after preparation, quickly cool feeds to feeding temperature by holding the bottle or feeding cup under running tap water, or by placing in a container of cold or iced water

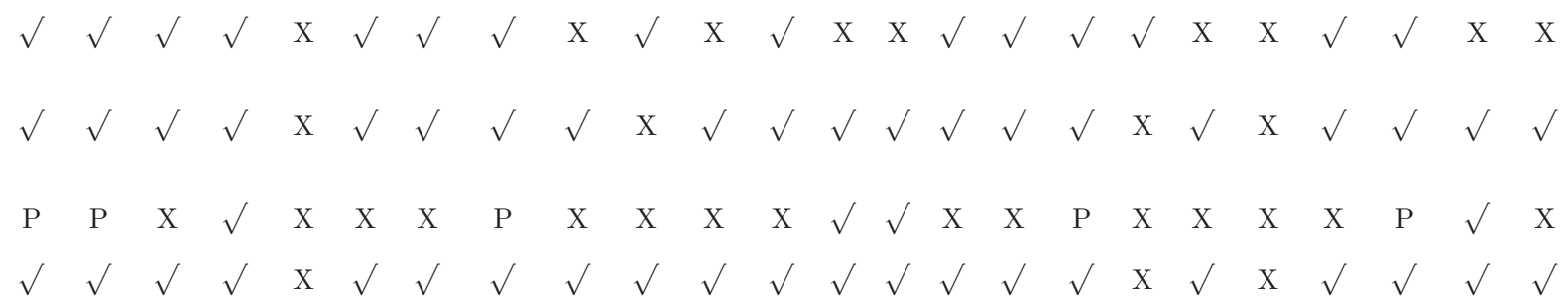




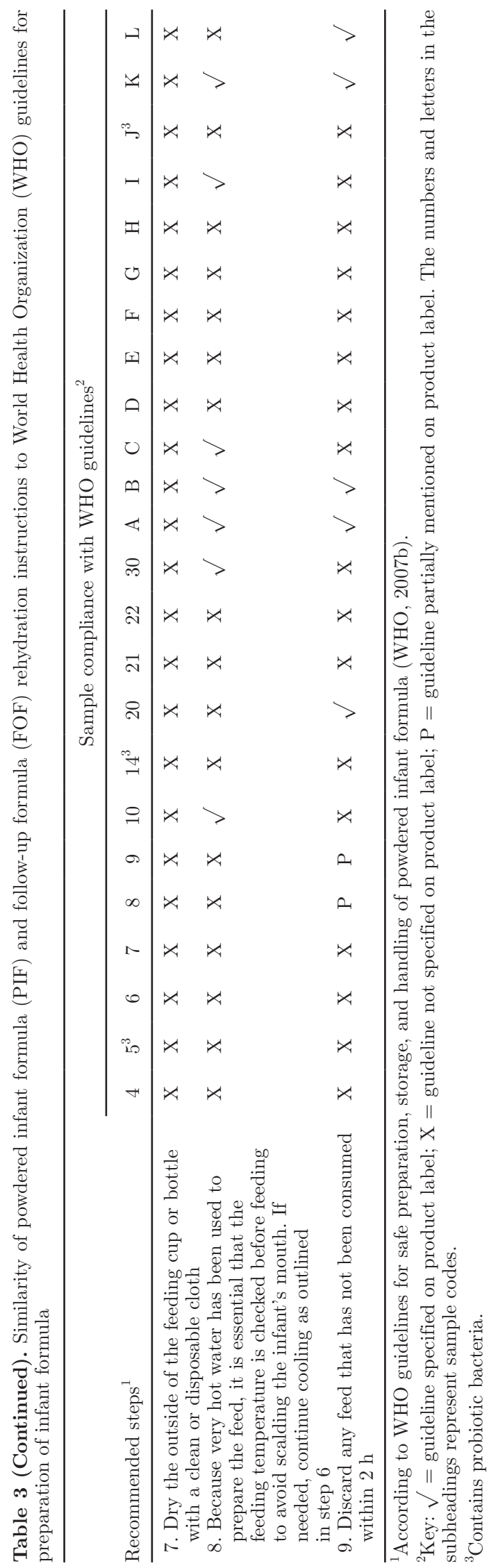

Escherichia coli, and Klebsiella spp., from various infant milk and infant food samples.

The dose-response relationship of Enterobacteriaceae in milk powders has not been established, but its absence in the product provides extra protection to newborns, especially to premature, immunocompromised, and low- $(<2,500 \mathrm{~g})$ and very low $(<1,500 \mathrm{~g})$-birth-weight babies, in case multiplication of the organism occurs during preparation, storage, or administration of the infant food (Muytjens et al., 1988; FAO/WHO, 2004). The impact of infection largely depends on the disease contracted by the neonates (Reij et al., 2009), but Bowen and Braden (2008) have reported that, of infants suffering from meningitis, a considerable percentage do not survive, whereas those who do survive suffer severe sequelae. More recently, Joseph and Forsythe (2011) reported the association of $C$. sakazakii ST4 with the majority of neonatal meningitis cases over the past 30 yr. Despite the presence of Enterobacteriaceae in the samples, no outbreak or documented reports have been made in Malaysia pertaining to neonatal infection following consumption of any of the Enterobacteriaceaepositive products mentioned herein, or of any powdered infant formula for that matter.

Cronobacter was not detected in any of the samples analyzed in this study. Other studies have reported the presence of Cronobacter in various food products, including infant food and milk, but usually the organism was found in a very low percentage of the total samples tested. Reports by the FAO/WHO (2006) indicate a 2 to $22 \%$ incidence of Cronobacter spp. in PIF from various studies. Tudela et al. (2008) reported the absence of pathogenic bacteria in 156 rehydrated milk formulas examined in a hospital.

It is standard procedure that $10 \mathrm{~g}$ of sample be used for analysis. However, given the low frequency of Cronobacter incidences, Hoque et al. (2010) states that the organism may be better traced if larger volumes of sample are used. In addition to using larger volumes of sample, Iversen and Forsythe (2004) suggested the use of Cronobacter chromogenic medium to better detect the organism. This suggestion was made after chromogenic medium was observed to more effectively isolate Cronobacter (67/485 positive samples) compared with the conventional VRBGA method (Muytjens et al., 1988) adopted by the FDA, which yielded only 19/485 positive samples.

\section{Evaluation of Rehydration Instructions on Product Packaging}

The ease of application and clarity and consistency of rehydration instructions provided on infant milk products are important considerations when addressing 
guidance needs for the general public during preparation and management of infant food. By definition of the Codex Alimentarius Commission (revision 2007; CAC, 1981), infant formula is "a breast-milk substitute specially manufactured to satisfy, by itself, the nutritional requirements of infants during the first months of life up to the introduction of appropriate complementary feeding". The CAC describes FOF as "food intended for use as a liquid part of the weaning diet for the infant from the 6th month on and for young children". On the other hand, IF is described as "food processed and manufactured for the nutritional health of children in their first year of life" (Reference.MD, 2010).

The WHO has issued a set of guidelines on the safe preparation, storage and handling of powdered infant formula, which includes 2 sets of guidelines: preparation of PIF in care settings (WHO, 2007a) and preparation in the home (WHO, 2007b). The latter guidelines have been tabulated and how each PIF and FOF product conforms to them was evaluated (Table 3). Although the WHO publication is a guideline and not a standard by which manufacturers must comply with, it is important to note that some rehydration instructions on product labels may either be insufficient, ambiguous, or difficult to follow and may cause the improper handling of infant formula milk.

The 90 samples evaluated in this study consisted of 24 different PIF and FOF products. From these, $21 / 24$ rehydration instructions specified that bottles and utensils should be sterilized by boiling (Step A.4; WHO, 2007a,b). All sample labels directed that the proper amount of boiled water be transferred to a clean sterilized bottle (Step B.4); all but one specified that water should be brought to boil for use in formula preparation (Step B.3) and that the exact amount of formula should be added to it (Step B.5).

The FAO/WHO (2006) and WHO (2007a,b) recommended the use of water $>70^{\circ} \mathrm{C}$ for reconstitution of powdered infant formula, but none of the collated rehydration instructions indicated the use of water at this temperature. When milk is prepared at the recommended $70^{\circ} \mathrm{C}$, milk handlers should be aware of the importance of rapid cooling to avoid the multiplication of bacteria. From the different PIF and FOF product types, 9 mentioned specific temperatures ranging from 40 to $55^{\circ} \mathrm{C}$. These temperatures, at which feed may be given to infants, may have been recommended so that no further cooling would be required, as per Step B.6 of the WHO $(2007 \mathrm{a}, \mathrm{b})$ guidelines. However, it is important to note that at these temperatures, Cronobacter and other Enterobacteriaceae can grow (Chap et al., 2009). All other brands only mentioned for previously boiled water to be cool or lukewarm before addition of formula. These subjective temperature de- scriptions may contribute to the mishandling of infant formula and if subsequent growth and multiplication of microorganisms occurred due to these temperature errors, it would be difficult to trace and take corrective action.

The potential growth of Cronobacter in bottled reconstituted infant formula milk depends on several factors such as initial water temperature, temperatures of the rooms wherein the milk was prepared and stored, and reheating temperature and time (Rosset et al., 2007). Because of the small volumes of infant formula milk distributed to infants (roughly $30 \mathrm{~mL}$ ), Rosset et al. (2007) further stressed the importance of temperature control, as smaller volumes are more sensitive to temperature changes.

Six of the product types tested contained probiotic cultures, 3 were FOF, and the others were infant cereals. For a probiotic culture to maintain its beneficial characteristics in a food product, its viability should be maintained. Generally speaking, lower temperatures account for better stability and the higher the temperature, the shorter time required for the number or probiotic bacteria to decrease, ranging from several hours to minutes at 40 to $55^{\circ} \mathrm{C}$ and seconds at higher temperatures (Lee and Salminen, 2009). In cases where the infant product contains probiotic bacteria, special consideration must thus be given in terms of rehydration procedure as well as the handling of the rehydrated product. All the infant cereals with probiotics specified that water was to be heated and cooled to $40^{\circ} \mathrm{C}$, whereas 2 of the FOF (samples 5 and 14) product labels instructed the use of boiled water cooled to $45^{\circ} \mathrm{C}$. The other probiotic-containing FOF (sample J) label did not specify any temperature and no special instructions were provided.

Furthermore, 16/24 of the product labels did not provide specific keeping and disposal instructions for unused formula. The WHO recommends that formula that has not been consumed within $2 \mathrm{~h}$ should be discarded. Only 5 products gave specific instructions for handling unconsumed formula, whereas an additional 2 (samples 8 and 9) specified that a fresh batch of formula should be prepared for each feeding.

In Malaysia, in the late 1990s, it was reported that $9.6 \%$ of infants were born with a low weight $(<2,500$ g) and this represents the group that is at risk of consuming contaminated feed (Estuningsih and Abdullah Sani, 2008). Given this situation, possible Cronobacter contamination in developing countries such as Malaysia should be given more attention because hygienic conditions and facilities (such as clean running water) may not be at par with those in exporting countries, or may not always be available, thus increasing the risk of contamination, implicating high-risk groups. 
Contaminated water and contaminants on bottles and nipples are significant health concerns for formulafed infants (Morais et al., 1998; Morais et al., 2005). A study of over 2,000 infants less than 6 mo of age in the Philippines showed that consumption of even small amounts of contaminated liquids almost doubles their risk of diarrhea compared with fully breastfed infants (VanDerslice et al., 1994). Thus, when breastfeeding is not possible, it is suggested to minimize possible contamination of formula by constantly monitoring both raw materials and the production environment. Rehydration instructions for all infant-related products should be simple and easy to apply. For multiracial and multiethnic nations such as Malaysia, rehydration illustrations should be included on product packaging to assist those who do not understand the language on the product label and those who are not literate.

\section{CONCLUSIONS}

Results of this study showed that around $13 \%$ of PIF, FOF, and IF samples $(\mathrm{n}=90)$ commercially available in Malaysia had viable counts greater than the permitted $10^{4} \mathrm{cfu} / \mathrm{g}$ level. Enterobacteriaceae was detected in $14 \%$ (13/90) of the infant products analyzed. Rehydration instructions provided on product labels are generally comprehensive, but could be further improved to foster consistency with guidelines prescribed by the WHO and to cater to special consumer groups such as the less educated.

\section{ACKNOWLEDGMENTS}

The authors acknowledge research funding from the Ministry of Science, Technology and Innovation for the Science Fund (Putrajaya, Malaysia; 02-01-02SF0476) and the Ministry of Higher Education for the Fundamental Research Grant in Science (Putrajaya, Malaysia; UKM-ST-07-FRGS0034-2009). Contributions from the Research University Operatonal Funds (UKM-OUP-2012-127 and OUP-UKM-FST-2012) are also appreciated.

\section{REFERENCES}

Adams, M. 2007. Food hygiene in developing countries. Pages 326-335 in Hobbs' Food Poisoning and Food Hygiene. 7th ed. J. McLauchlin, and C. Little, ed. Edward Arnold, London, UK.

Biering, G., S. Karlsson, N. C. Clark, K. E. Jónsdóttir, P. Lúdvígsson, and O. Steingrímsson. 1989. Three cases of neonatal meningitis caused by Enterobacter sakazakii in powdered milk. J. Clin. Microbiol. 27:2054-2056.

Bowen, A. B., and C. R. Braden. 2008. Enterobacter sakazakii disease and epidemiology. Pages 101-125 in Enterobacter sakazakii. J. M. Farber and S. J. Forsythe, ed. ASM Press, Washington, DC.

CAC (Codex Alimentarius Commission). 1981. Standard for infant formula and formulas for special medical purposes intended for infants, Vol. CODEX STAN 72 1981. Formerly CAC/RS 72-1972. Adopted as a worldwide standard 1981. Amended 1983, 1985 , 1987. Revision 2007. CAC, Rome, Italy.

Chap, J., P. Jackson, R. Siqueira, N. Gaspar, C. Quintas, J. Park, T. Osaili, R. Shaker, Z. Jaradat, S. H. P. Hartantyo, N. Abdullah Sani, S. Estuningsih, and S. J. Forsythe. 2009. International survey of Cronobacter sakazakii and other Cronobacter spp. in follow-up formulas and infant foods. Int. J. Food Microbiol. 136:185-188.

EC (European Commission). 2005. Regulation no. 2073/2005 of 15 November 2005 on microbiological criteria for foodstuffs. Off. J. Eur. Union L338:1-26.

Estuningsih, S., and N. Abdullah Sani. 2008. Powdered infant formula in developing and other countries-Issues and prospects. Pages 221-234 in Enterobacter sakazakii. J. M. Farber J. and S. J. Forsythe, ed. ASM Press, Washington, DC.

FAO/WHO (Food and Agriculture Organization of the United Nations/World Health Organization). 2004. Enterobacter sakazakii and other microorganisms in powdered infant formula: Meeting report. Microbiological Risk Assessment Series 6. WHO/FAO, Geneva, Switzerland.

FAO/WHO (Food and Agriculture Organization of the United Nations/World Health Organization). 2006. Enterobacter sakazakii and Salmonella in powdered infant formula: Meeting report. Microbiological Risk Assessment Series 10. WHO/FAO, Geneva, Switzerland.

Food Act. 2006. Food Act 1983 (Act 281) and Regulations. International Law Book Services, Kuala Lumpur, Malaysia.

Gilbert, R. J., J. de Louvois, T. Donovan, C. Little, K. Nye, C. D. Ribeiro, J. Richards, D. Roberts, and F. J. Bolton. 2000. Guidelines for the microbiological quality of some ready-to-eat foods sampled at the point of sale. Commun. Dis. Public Health 3:163-167.

HMSO. 1995. The dairy products (hygiene) regulations. Statutory Instrument 1995 No. 1086. Her Majesty's Stationery Office (HMSO), London, UK.

Hoque, A., T. Ahmed, M. Shahidullah, A. Hossain, A. Mannan, K. Noor, K. Nahar, M. Ilias, and D. Ahmed. 2010. Isolation and molecular identification of Cronobacter spp. from powdered infant formula (PIF) in Bangladesh. Int. J. Food Microbiol. 142:375-378.

ISO (International Organization for Standardization). 2004. Microbiology of food and animal feeding stuffs - Horizontal methods for the detection and enumeration of Enterobacteriaceae - Part 1: Detection and enumeration by MPN technique with pre-enrichment. ISO 21528-1:2004. Accessed Oct. 10, 2010. http://www.iso.org/iso/iso_ catalogue/catalogue_tc/catalogue_detail.htm?csnumber $=34565$.

Iversen, C., and S. Fanning. 2009. Introductory note to the Cronobacter. Int. J. Food Microbiol. 136:151.

Iversen. C., and S. Forsythe. 2004. Isolation of Enterobacter sakazakii and other Enterobacteriaceae from powdered infant formula milk and related products. Food Microbiol. 21:771-777.

Joseph, S., and S. Forsythe. 2011. Association of Cronobacter sakazakii ST4 with neonatal infections. Emerg. Infect. Dis. 17:1713-1715.

Kucerova, E., S. Joseph, and S. Forsythe. 2011. The Cronobacter genus: Ubiquity and diversity. Qual. Assur. Safety Crops Foods $3: 104-122$

Lee, Y. K., and S. Salminen. 2009. Handbook of Probiotics and Prebiotics. 2nd ed. John Wiley \& Sons Inc., Hoboken, NJ.

Marino, D. D. 2007. Water and food safety in the developing world: Global implications for health and nutrition of infants and young children. J. Am. Diet. Assoc. 107:1930-1934.

Morais, T. B., M. B. Morais, and D. M. Sigulem. 1998. Bacterial contamination of the lacteal contents of feeding bottles in metropolitan São Paulo, Brazil. Bull. World Health Organ. 76:173-181.

Morais, T. B., D. M. Sigulem, H. de Sousa Maranhão, and M. B. de Morais. 2005. Bacterial contamination and nutrient content of home-prepared milk feeding bottles of infants attending a public outpatient clinic. J. Trop. Pediatr. 51:87-92.

Muytjens, H. L., H. Roelofs-Willemse, and G. H. J. Jaspar. 1988. Quality of powdered substitutes for breast milk with regard to members of the family Enterobacteriaceae. J. Clin. Microbiol. 26:743-746.

Rautava, S. 2007. Potential uses of probiotics in the neonate. Semin. Fetal Neonatal Med. 12:45-53. 
Reference.MD. 2010. The Encyclopedia of Medical Concepts. Accessed Sep. 18, 2010. http://www.reference.md/files/D007/mD007225. html.

Reij, M. W., I. Jongenburger, E. Gkogka, L. G. M. Gorris, and M. H. Zwietering. 2009. Perspective on the risk to infants in the Netherlands associated with Cronobacter spp. occurring in powdered infant formula. Int. J. Food Microbiol. 136:232-237.

Roberts, D., and M. Greenwood. 2003. Pages 65-75 in Practical Food Microbiology. 3rd ed. Blackwell Publishing, Malden, MA.

Rosset, P., V. Noel, and E. Morelli. 2007. Time-temperature profiles of infant milk formula in hospitals and analysis of Enterobacter sakazakii growth. Food Contr. 18:1412-1418.

Saavedra, J. M., A. Abi-Hanna, N. Moore, and R. H. Yolken. 2004 Long-term consumption of infant formulas containing live probiotic bacteria: Tolerance and safety. Am. J. Clin. Nutr. 79:261-267.

Simmons, B. P., M. S. Gelfand, M. Haas, L. Metts, and J. Ferguson. 1989. Enterobacter sakazakii infections in neonates associated with intrinsic contamination of a powdered infant formula. Infect. Control Hosp. Epidemiol. 10:398-401.

Tirado, M. C., R. Clarke, L. A. Jaykus, A. McQuatters-Gollop, and J. M. Frank. 2010. Climate change and food safety: A review. Food Res. Int. 43:1745-1765.
Tudela, E., J. Croizé, A. Lagier, and M. R. Mallaret. 2008. Microbiological monitoring of milk samples and surface samples in a hospital infant formula room. Pathol. Biol. (Paris) 56:272-278. (Original article in French.)

VanDerslice, J., B. Popkin, and J. Briscoe. 1994. Drinking-water quality, sanitation, and breast-feeding: Their interactive effects on infant health. Bull. World Health Organ. 72:589-601.

Viljanen, M., E. Savilahti, T. Haahtela, K. Juntunen-Backman, R. Korpela, T. Poussa, T. Tuure, and M. Kuitunen. 2005. Probiotics in the treatment of atopic eczema/dermatitis syndrome in infants: A double-blind placebo-controlled trial. Allergy 60:494-500.

WHO (World Health Organization). 2007a. How to prepare powdered infant formula in care settings. Department of Food Safety, Zoonoses and Foodborne Diseases, WHO, and the Food and Agriculture Organization of the United Nations (FAO), Geneva, Switzerland.

WHO (World Health Organization). 2007b. Safe preparation, storage and handling of powdered infant formula: Guidelines. WHO and the Food and Agriculture Organization of the United Nations (FAO), Geneva, Switzerland. 